\title{
A TiPologia do ANACRONISMO EM Borges
}

\author{
Gustavo Ponciano Cunha de Oliveira \\ gponciano.co@gmail.com
}

A relação que Jorge Luis Borges (1899-1986) trava com os textos que lê é fundamental para sua poética - fato largamente identificado pela crítica especializada. ${ }^{1}$ Essa importância responde ao que chamamos de caráter metonímico da leitura em Borges: a ideia de que, diante de seus textos, ao pronunciarmos com o autor qualquer dos termos da relação leitura / escrita / releitura / reescrita, todos os outros são simultaneamente evidenciados. ${ }^{2}$ A relação travada é não passiva: o trabalho do leitor borgiano está inserido em uma rede de enunciações virtualmente infinita; os textos sempre gerarão novos textos, prontos a serem mais uma vez lidos, glosados, criticados, traduzidos. Na esteira de Pierre Menard, há um sem número de leitores dispostos a lê-lo. Não há texto definitivo. "El concepto de texto definitivo no corresponde sino a la religión o al cansancio" (BORGES, 1974a, p. 239). A leitura instigada por Quixote não se encerra

${ }^{1}$ Para citar um exemplo, o recorrentemente lembrado Emir Rodríguez Monegal (1980, p. 91): "Implicitamente, Borges postula que reler, traduzir, são parte da invenção literária. E talvez que reler e traduzir são a invenção literária. Daí a necessidade implícita de uma poética da leitura”.

${ }^{2}$ Valemo-nos aqui do que Compagnon (1996, p. 25) chama de caráter metonímico da citação: sua capacidade de "designar ao mesmo tempo duas operações - uma, de extirpação, outra, de enxerto - e ainda o objeto dessas duas operações - o objeto extirpado e o objeto enxertado - como se ele permanecesse o mesmo em diferentes estados". Leitura (solicitação e excitação) e escrita (reescrita) têm como substância a citação. 
em Menard ou em sua enciclopédia particular (Nietzsche, Russell, Poe, Valéry, William James...), em que acomoda sua leitura de Cervantes. Ela segue, tão mais próxima do que se pode imaginar: surge, emergente, no solicitado narrador do conto ${ }^{3}$ de Borges, que identifica o estilo de Menard em um trecho do Quixote nunca antes por este premeditado:

Noches pasadas, al hojear el capítulo XXVI -no ensayado nunca por élreconocí el estilo de nuestro amigo y como su voz en esta frase excepcional: las ninfas de los ríos, la dolorosa y húmeda Eco. Esa conjunción eficaz de un adjetivo moral y otro físico me trajo a la memoria un verso de Shakespeare, que discutimos una tarde:

Where a malignant and a turbaned Turk... (BORGES, 1974, p. 447)

No fragmento, quem opera a ferramenta discursiva à qual nos dedicaremos neste artigo, o anacronismo, não é mais Menard, mas o narrador que, entre outras entrelinhas, está a nos revelar que somos capazes e que estamos sempre a fragmentar e reordenar textos, mesmo que neguemos ou que não tenhamos consciência do trabalho. O pesquisador cita o narrador, que cita e glosa Menard, que cita e comenta Cervantes todos se valendo de diversas outras citações, metonimicamente operadas, para compor seus textos.

Indubitavelmente, a discussão aqui aberta exige a remissão à ideia de precursor em Borges, especificamente o conceito que surge em "Kafka y sus precursores", texto que integra Otras inquisiciones (1953) e previamente publicado no periódico La Nación, em 19 de agosto de 1951. Compreendemos que o debateali proposto por Borges apresenta a proposta de um de seus fundamentos literários: a leitura crítica, aquela consciente de seu lugar histórico e estético, sabedora da força de sua enunciação, opera, de forma destacada, a relação que trava com seus precursores. "Kafka y sus precursores" discute ética e competência de leitura. São seus protocolos que permitem a Borges reconfigurar, reordenar e combinar, em

3 "Pierre Menard, autor del Quijote" é o único texto de Borges que aparece, traduzido para o inglês, entre os 77 ensaios em The Oxford book of Latin American essays, organizado por Stavans (1997, p. 153-161). Outro famoso exemplo de instabilidade genérica em Borges é "El acercamiento a Almotásim": a resenha do falso livro de Mir Bahadur Alí aparece pela primeira vez em uma coletânea de ensaios, Historia de la eternidad (1936). É integrado às coletâneas de contos El jardín de senderos que se bifurcan, em 1941, e Ficciones, a partir de 1944. Retorna a Historia de la eternidad nas edições de 1953 e 1961, livro no qual permanece para a publicação das Obras completas, em 1974 (Cf. ROJAS, 2007, p. 116). 
suas próprias composições (ficcionais ou não; poéticas ou não), textos e autores que elege como os de excelência: sua enciclopédia, sua tradição. Esta presença do heterogêneo (dos que vieram antes) é manifestação, em alto grau de explicitação, da memória que a literatura guarda de si mesma.

Ao aproximar o famoso ensaio de Borges de dois outros textos do autor portenho, "La eternidad y T. S. Eliot" e "El escritor argentino y la tradición", e ao compará-los com "Tradition and the individual talent", de Eliot, ${ }^{4}$ Castro (2007) localiza um vínculo primordial ao conceito de precursor presente em "Kafka y sus precursores": a ideia de tradição particular a Borges. Seu objetivo na pesquisa é verificar as modificações que Borges, com o intuito de gerar seu particular conceito de precursor, aplica ao pensamento eliotiano. Defendemos a tese de que Castro torna evidente que observar o precursor implica em conceder a devida atenção ao conceito de tradição.

Castro (2007) destaca inicialmente o fato de Borges, em "La eternidad y T. S. Eliot",5 construir as citações que faz de Eliot: dispõe em um único fragmento trechos de parágrafos diferentes e os traduz com liberdade. Dessa forma, "el texto construido por Borges presenta de una manera más concisa y vigorosa que el original de Eliot los argumentos que justifican la noción de que 'el pasado es modificado por el presente”" (CASTRO, 2007, p. 11). Dessa forma, o fragmento "Quem quer que haja aceito essa ideia de ordem, de forma da literatura europeia ou inglesa, não julgará absurdo que o passado deva ser modificado pelo presente tanto quanto o presente esteja orientado pelo passado" (ELIOT, 1989, p. 39-40)6 transforma-se, reconfigurado e traduzido, em "El pasado es modificado por el presente, el presente es dirigido por el pasado” (BORGES, 2002b, p. 50).

4 Como aponta Castro (2007, p. 9), "Tradition and individual talent" foi redigido em 1917. Porém, foi publicado pela primeira vez, em duas partes, apenas em setembro e dezembro de 1919, no periódico Egoist e reimpresso no primeiro livro em prosa de Eliot, The sacred wood (1920). Mais tarde, foi incluído em Selected essays 1917-1932 (1932) (Cf. WHITE, 2007). A nota de Ivan Junqueira à edição brasileira (ELIOT, 1989, p. 238) não faz menção à publicação em Egoist.

5 Publicado pela primeira vez na portenha Poesía, Revista Internacional de Poesía, v. 1, n. 3, jul. 1933. Seu primeiro parágrafo passou a integrar o ensaio "Historia de la eternidad", publicado em 1936 na coletânea homônima.

6 "Whoever has approved this idea of order, of the form of European, of English literature, will not find it preposterous that the past should be altered by the present as much as the present is directed by the past" (ELIOT, 1999, p. 526, apud CASTRO, 2007, p. 11). 
Essa liberdade de leitura empreendida sobre o texto de Eliot é crucial para que Borges, ao tratar da tradição literária em "Kafka y sus precursores", inverta as propostas centrais do autor de "Tradition and the individual talent", como aponta Castro (2007, p. 13): Eliot "propone fortalecer la continuidad entre la producción literaria y artística actual y la del pasado, dado que los escritores desarrollaban la 'conciencia del pasado' e incorporan esta conciencia en las nuevas obras de arte que producen". Borges, pelo contrário, não pensa em continuidade, mas em "mirada retrospectiva, descubrir la diferencia actual en la producción literaria del pasado" (p. 13). Em outros termos, ao criarem suas enunciações no presente sobre as obras de tempos idos, os textos atuais nos ajudam a compreender os textos do passado e a determinar o que é a tradição.

Essa proposta anti-hierárquica estende-se ao conceito de tradição e surge já no título de outro texto acionado por Castro (2007, p. 14) em sua leitura: "El escritor argentino y la tradicción".7 Borges, em seu ensaio, contraria peronistas e hispanófilos ao excluir, respectivamente, a literatura gauchesca e a literatura peninsular como as precursoras, a tradição que teria gerado a literatura argentina. Para Borges (1974a, p. 272), "nuestra tradición es toda la cultura occidental". "Creo que los argentinos, los sudamericanos en general, estamos en una situación análoga; podemos manejar todos los temas europeos, manejarlos sin supersticiones, con una irreverencia que puede tener, y ya tiene, consecuencias afortunadas" (p. 273). E nesse ponto, mais uma vez, defende Castro (2007, p. 14), Borges afasta-se de Eliot. Enquanto o anglo-americano defende a ideia de que "a evolução de um artista é um contínuo autossacrifício, uma contínua

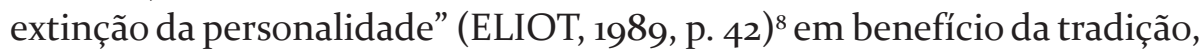
"Borges arguye que es necesario mostrar irreverencia, en otras palabras libertad, inclusive superioridad" (CASTRO, 2007, p. 14). A tradição, nosso patrimônio, é o universo, defende Borges.

Portanto, nos parece ser portador de uma contradição o recorrente comentário de que, para compor seu próprio ideário, Borges apropria-se, quiçá de forma maliciosa, de concepções do criador de “Tradition and

7 Originalmente, palestra proferida no Colegio Libre de Estudios Superiores, em 19 de dezembro de 1951. Publicado pela primeira vez em Cursos y conferencias, ano 21, v. 42, n. 250, 251 e 252, Buenos Aires, jan., fev., mar. 1953. Posteriormente recolhido em Discusión (Cf. FERNANDES, 2005).

8 "The progress of an artist is a continual self-sacrifice, a continual extinction of personality” (ELIOT, 1999, p. 527, apud CASTRO, 2007, p. 14). 
the individual talent”. Tal comentário desconhece Borges: baseia-se em regras de pureza, o original e o exclusivo tratamento de fidelidade que a ele deve ser dispensado (em que se baseiam as acusações de malícia, plágio, crime), para referir-se a textos que operam anacronismos deliberados. Criar seu precursor (tal qual Borges cria Eliot) é modificar a percepção que se tem dele (de seus textos, dos fragmentos de seus textos) por meio de um trabalho de constante atualização de enunciados.

É nos dedicando a esse ponto que pensamos contribuir para os estudos borgianos e literários que observam não apenas as relações do texto (de Borges) com os textos primeiros (a tradição, os precursores), mas também os que investigam o discurso crítico e teórico do autor portenho sobre o tema. Assim, como anteriormente declarado sobre o vínculo fundamental entre os conceitos de precursor e tradição em Borges, nos parece que é preciso adicionar a essa convergência conceitual um terceiro elemento, ainda não devidamente observado pela crítica especializada: o anacronismo deliberado, que, na leitura proposta, éa ferramenta discursiva fundamental em Borges. Assim, dar a devida atenção ao anacronismo nos parece fornecer aos estudos dos conceitos de precursor e tradição o instrumento textual que os põe em prática.

Iniciaremos apresentando uma tipologia do anacronismo, localizada nos textos de Borges, e formada por duas categorias: a positiva, o anacronismo deliberado; a negativa, que chamamos de anacronismo tautológico. Na sequência, observaremos como o anacronismo deliberado ocorre textualmente na leitura que o autor faz de Walt Whitman em um de seus ensaios.

\section{ANACRONISMO}

Em Discusión (1932), encontramos o primeiro debate de Borges sobre o anacronismo. Além do prólogo, ao qual recorreremos mais adiante, há na coletânea um instigante ensaio, sobre a arte cinematográfica, fundamental para compreender como o autor concebe e tipifica o anacronismo: "Films", que é a reunião de dois artigos publicados na revista Sur, em agosto de 1931 e maio de $1932 .{ }^{9}$ A partir desse artigo, e fazendo

${ }_{9}$ Respectivamente: “Die Mörder Dimitri Karamasoff, dir. Fedor Ozep; The docks of New York e Morrocco, dir. Josef von Sternberg; City lights, dir. Charles Chaplin" e "Street Scene, dir. King Vidor". 
ainda a remissão a outros ensaios do autor (não apenas aos presentes no livro de 1932), assim como a "Pierre Menard, autor del Quijote", sugerimos uma tipologia borgiana de anacronismo formada por duas categorias opostas: o anacronismo deliberado (o positivo, criativo, crítico em relação ao texto primeiro, programado e controlado por aquele que o opera); o anacronismo tautológico (o negativo, descontextualizado, subordinado ao texto primeiro, mera redundância acrítica).

Partamos para a leitura de "Films" e de seus exemplos de anacronismo tautológico.

A primeira qualidade de El asesino Karammasoff (1931), segundo Borges, é a de desvencilhar-se com destreza de problemas que localizou nas versões anteriores, entre os quais "la tautología o vana repetición de imágenes equivalentes” (BORGES, 1974a, p. 222). Borges avalia-se um felizardo por não ter lido o romance de Dostoiévski no qual o filme é baseado; assim, pode assisti-lo sem exercitar a improdutiva aferição de tautologias: "la continua tentación de superponer el espectáculo actual sobre la recordada lectura, a ver si coincidían. Así, con inmaculada prescindencia de sus profanaciones nefandas y de sus meritorias fidelidades -ambas inimportantes-, el presente film es poderosísimo" (p. 222). A leitura ${ }^{10}$ tautológica é, aqui, mera comparação com fins de localizar similaridades e diferenças. Está baseada em regras de pureza, a fidelidade e o original. Não é esse o confronto que Borges promove entre as três versões da adaptação de Irmãos Karamazov ao cinema. Preocupam-lhe questões estéticas. Em uma das versões alemãs, aponta os equívocos: a simbologia lúgubre, as imagens satânicas, a obscenidade, as explicações teratológicas e a tautologia; na adaptação soviética: a ausência de caracteres, a concentração no recurso fotográfico, o discurso ideológico. Agradam-lhe, além das destrezas do diretor Fedor Ozep ao escapar dos enganos das adaptações anteriores, a montagem alucinatória, a fotografia e a cena de genuína felicidade que segue a sequência do assassinato; em última instância, Borges aprecia a invenção e a execução de Ozep.

City lights (1931), de Charles Chaplin, é a seguinte película avaliada por Borges. Recebe duras críticas. A que mais nos interessa aqui é

${ }^{10}$ Recordemos que, em Borges e, por extensão, na crítica nele especializada, é impossível escapar ao caráter metonímico da leitura. Ao criticar certa leitura, critica-se também certa concepção de escrita, releitura e reescrita. 
fundada no anacronismo tautológico. "Su destartalado argumento pertenece a la difusa técnica conjuntiva de hace veinte años. Arcaísmo y anacronismo son también géneros literarios, lo sé; pero su manejo deliberado es cosa distinta de su perpetración infeliz" (BORGES, 1974a, p. 223). ${ }^{11} \mathrm{O}$ filme de Chaplin é uma reunião dos pequenos percalços de uma história sentimental que redunda; repete, inclusive, sem adicionar qualquer reflexão, cenas de outros filmes, como a do elefante e do Vagabundo empregado como varredor de rua - "reedición facsimilar del incidente del basurero troyano y del falso caballo de los griegos" (p. 223) em The private life of Helen of Troy (1931). City lights ainda não se enquadra, segundo Borges, nem na categoria dos filmes reais, nem na dos que se fundam na "voluntaria irrealidad", presente, por exemplo, em Buster Keaton, Frank Borzage, Sergei Eisenstein e nas primeiras produções do próprio Chaplin. Em seu então novo filme, à exceção do Vagabundo e da moça cega, todos os personagens são "temerariamente normales”, defende o ensaísta. Destacamos, nos comentários de Borges a City lights, o fato de que anacronismo e irrealidade vêm qualificados por adjetivos (deliberado e voluntária) que apontam a necessidade de controle autoral sobre as ferramentas estéticas das quais se vale o criador em suas obras.

Josef von Sternberg e Cecil B. DeMille são os próximos avaliados por Borges. A crítica diz respeito à recriação cenográfica e à figuração, ou seja, à ambientação. Admirador de Sternberg, Borges (1974a, p. 223) não deixa de apontar o que acredita ser equivocado em seu filme. Morocco (1930) peca por seu anacronismo tautológico: a acumulação de figurantes e o excesso de marcações da cor local, que têm como fonte o desejo de fidelidade. "Sternberg, para significar Marruecos, no ha imaginado un medio menos brutal que la trabajosa falsificación de una ciudad mora en suburbios de Hollywood, con lujo de albornoces y piletas y altos muecines guturales que preceden el alba y camellos con sol”. Ao citar DeMille, Borges faz referência, sem nominar filmes, aos

${ }^{11}$ Borges, em outro trecho de "Films", no qual comenta a ideia, para ele equivocada, de que a cinematografia soviética obliterara a estadunidense, também usa o termo literatura para referir-se ao cinema: "Se olvidó que era imposible contraponer algunas buenas o excelentes violencias (Iván el Terrible, El acorazado Potemkin, tal vez Octubre) a una vasta y compleja literatura, ejercitada con desempeño feliz en todos los géneros, desde la incomparable comicidad (Chaplin, Buster Keaton y Langdon) hasta las puras invenciones fantásticas: mitología del Krazy Kat y de Bimbo" (BORGES, 1974a, p. 224). 
dramas bíblicos do diretor. ${ }^{12}$ Compara o recurso dos figurantes em excesso, segundo ele, uma das tediosas convenções do cinema de Hollywood, com as técnicas da contradição e do conflito do cinema soviético, exemplificadas com O encouraçado Potemkin (1925), de Eisenstein:

Los rusos descubrieron que la fotografía oblicua (y por consiguiente deforme) de un botellón, de una cerviz de toro o de una columna, era de un valor plástico superior a la de mil y un extras de Hollywood, rápidamente disfrazados de asirios y luego barajados hasta la total vaguedad por Cecil B. de Mille (BORGES, 1974a, p. 224).

A reflexão de Borges sobre DeMille (e sua anacrônica dedicação à ambientação) é complementada no comentário do autor a The sign of the cross (1932), publicado em junho de 1933 em "Cine: cinco breves noticias", nos Cuadernos Mensuales de Cultura do número dois da portenha Selección.

Cecil B. de Mille ignora con perfección que la reconstrucción de personajes tan remotos como los mártires cristianos circenses y los perseguidores romanos, debe ser un problema. No recurre a la tentativa de comprensión ni al voluntario anacronismo: le basta con disfraces, con leones, con barbas postizas, con himnos luteranos y letra gótica (BORGES, 2002a, p. 45).

Mais uma vez éo exercícioanacrônico de mera tautologia, subordinado à aparente fidelidade, que desagrada Borges. Frente à tentativa de recriação técnica da Roma de Nero pela ambientação, certamente os hinos luteranos e as letras góticas destacados pelo ensaísta não são recursos anacrônicos que auxiliam na elucidação do que é e quais são as implicações da perseguição romana aos cristãos. Nada adicionam para fomentar a reflexão. Pelo contrário: embaralham as duas enunciações, a do texto bíblico e a do discurso do filme sobre o texto primeiro que lê. Como em um dos precursores de Menard, os livros parasitários que deslocam personagens (antes de tudo os valores que formam seus caracteres) para colocá-los à prova em outros tempos, The sign of the cross atribui caráter romântico a um ficcional oficial romano, Marcus Superbus, anacrônico prefeito de Roma durante o império de Nero, e à relação que ele trava

${ }^{12}$ Até meados de 1932, data de publicação do segundo ensaio que forma "Films", DeMille já havia lançado, nos Estados Unidos, dois dramas bíblicos: The King of Kings (1927) e The Ten Commandments (1923). 
com a cristã Mercia. A crueldade de Marcus encontra contraponto justamente no amor que passa a sentir pela mulher que, antes, perseguia implacavelmente. A cena final provavelmente estimulou a reflexão de Borges. Mercia faz prevalecer o primeiro mandamento do decálogo de Moisés. O amor a Deus supera o amor a Marcus e toda a possibilidade de felicidade no matrimônio por ele proposto. Crédula na paradisíaca vida eterna, não renuncia à sua fé, ato que garantiria sua vida: segue para a morte na arena. $\mathrm{O}$ anacronismo acrítico completa-se com a reação de Marcus: no último instante, na escadaria que conduz à morte, o amor por Mercia o faz entregar-se à fé cristã e seguir, abraçado à amada, ao amor eterno que supera a dor terrena (Cf. THE SIGN, 2011).

Assim configura-se o anacronismo tautológico: em The sign of the cross, figurinos e cenários falsificam a Roma do século I para que o amor romântico conduza à redenção em resposta a um princípio catequético que redunda, independentemente do tempo e do espaço, na representação.

\section{PIERRE MENARD}

Usualmente, ao falar-se de anacronismo em Borges, a remissão imediata é a um famoso fragmento de "Pierre Menard, autor del Quijote", ${ }_{13}$ de El jardín de senderos que se bifurcan (1941), posteriormente recolhido em Ficciones (1944): "Menard (acaso sin quererlo) ha enriquecido mediante una técnica nueva el artedetenidoy rudimentariodela lectura: la técnica del anacronismo deliberado y de las atribuciones erróneas" (BORGES, 1974b, p. 450). O narrador do conto de Borges faz, nesse instante, a exposição do mecanismo fundamental da obra invisível de Menard. Claire de Obaldia (2005, p. 393, tradução nossa) a classifica como a primeira regra da relação que os textos travam com os textos primeiros que acionam, aquela "que compreende que a 'redundância' ou a 'tautologia' é uma noção relativa ao enunciado e não à enunciação, a qual permanece um acontecimento sempre único e não reprodutível". ${ }^{14}$ Estamos diante da máxima ferramenta intertextual de Borges, o deliberado manejo de anacronismos.

${ }_{13}$ Publicado pela primeira vez na portenha Sur, ano 9, n. 56, maio 1939.

${ }_{14}$ "qui veut qui la 'redondance' ou la 'tautologie' soit un notion relative à l'énoncé et non à l'énonciation qui demeure quant à elle un événement toujours unique et non reproductible". 
Não apenas a categoria positiva, a do anacronismo deliberado, está descrita em "Pierre Menard, autor del Quijote". As duas categorias da tipologia, que surgem nos debates de Borges em Discusión, aparecem também no conto.

Seu segundo tipo, o anacronismo tautológico, contraponto à categoria positiva do anacronismo deliberado, aparece em uma declaração jocosa de Menard, proferida em discurso indireto pelo narrador, logo após a apresentação dos precursores do personagem-autor - ou seus precursores prontos a serem suplantados pela idiossincrasia presente no plano criativo e crítico de Menard:

\begin{abstract}
Dos textos de valor desigual inspiraron la empresa. Uno es aquel fragmento filológico de Novalis -el que lleva el número 2005 en la edición de Dresdenque esboza el tema de la total identificación con un autor determinado. Otro es uno de esos libros parasitarios que sitúan a Cristo en un bulevar, a Hamlet en la Cannebiére o a don Quijote en Wall Street. Como todo hombre de buen gusto, Menard abominaba de esos carnavales inútiles, sólo aptos -decíapara ocasionar el plebeyo placer del anacronismo o (lo que es peor) para embelesarnos con la idea primaria de que todas las épocas son iguales o de que son distintas (BORGES, 1974b, p. 446)..$^{15}$
\end{abstract}

Novalis, para compreender um autor em seu exercício filológico-hermenêutico, defende a total identificação do leitor com seu objeto de estudo. Menard, repetidas vezes ao longo do conto de Borges, deixa manifesto seu desejo de continuar a ser Menard, e não Cervantes, para alcançar o Quixote. Além disso, há na proposta novaliana o princípio de leitura unívoca, a ideia de que existe um valor original e, consequentemente, uma exclusiva interpretação correta de um texto, aqui baseada no "pressuposto de que uma obra literária pode ser explicada pela referência à individualidade criadora do autor" (HILLIS MILLER, 1995b, p. 81). Parece-nos que Menard, consciente do lugar de sua enunciação, e do caráter ético que é assumi-lo, prontifica-se ao que Hillis Miller (1995b, p. 85-86) chama de leitura não canônica, "uma disposição para reconhecer o inesperado, talvez mesmo o chocante e o escandaloso, presente até em obras canônicas".

${ }^{15} \mathrm{O}$ valor desigual dos dois textos que inspiram Menard, nos parece, está no assombro da proposta de Novalis, a ideia de que um homem pode tornar-se outro, que inexiste no segundo texto, e da qual encontramos variantes ao longo da produção de Borges. "El impostor inverosímil Tom Castro", de Historia universal de la infamia (1935) e "Los teólogos", de El Aleph (1949) são exemplos. 
A leitura não canônica não é fazer a obra significar o que deseja o leitor, nem é simplesmente um relativismo crítico ou a transferência da responsabilidade de todo o significado a quem lê. É antes uma reação às exigências das palavras nas páginas, ao que elas dizem e não ao que gostaríamos que dissessem. Menard tem consciência histórica e sabe que seu estabelecimento enquanto leitor é contingencial. Destaca, mais de uma vez, qual é o lugar de Cervantes e do Quixote na história da literatura, como se acomodam em sua própria enciclopédia, e quais as relações que estabelecem com a história do pensamento. Cervantes continua a dizer o que disse Cervantes. Menard apenas reage às suas palavras aplicando seu próprio repertório:

Por ejemplo, examinemos el capítulo XXXVIII de la primera parte, "que trata del curioso discurso que hizo don Quixote de las armas y las letras”. Es sabido que D. Quijote (como Quevedo en el pasaje análogo, y posterior, de La hora de todos) falla el pleito contra las letras y en favor de las armas. Cervantes era un viejo militar: su fallo se explica. ¡Pero que el don Quijote de Pierre Menard - hombre contemporáneo de La trahison des clercs y de Bertrand Russell reincida en esas nebulosas sofisterías! (BORGES, 1974b, p. 448-449)

O "estoque de cores" (COMPAGNON, 1996, p. 21), entre Cervantes e Menard, é diverso e está manifesto com mais potência no ato de enunciação que no próprio enunciado (o qual se acomoda de forma diversa entre os recortes diversos, a enciclopédia, que compõem os dois diferentes discursos - no caso de Menard, os fragmentos do Quixote surgem entre seus comentários sobre a obra: sua crítica literária na qual aciona, entre outros, textos que Cervantes nunca leu). O projeto de ambos é diverso. Na obra (crítica) de Menard, seu capítulo XXXVIII, por exemplo, responde a "su hábito resignado o irónico de propagar ideas que eran el estricto reverso de las preferidas por él” (BORGES, 1974b, p. 449).

Por esses motivos, Novalis é suplantado pela estratégia de composição de Menard.

Retomemos o segundo "precursor" de Menard: um desses livros parasitários que deslocam os personagens de seus contextos originais, transportando-os a um universo estranho. Os exemplos citados são Cristo em um bulevar, Hamlet na Cannabiére e Quixote em Wall Street. A princípio, pode parecer que estamos diante de uma leitura diametralmente oposta àquela associada a Novalis: os três personagens seriam atualizados ao serem transpostos a outros tempos e espaços. Mas esse anacronismo é também portador de uma tautologia: Jesus permanecerá misericordioso; 
Hamlet, hesitante; Quixote, excêntrico. Se os resultados da misericórdia ou da hesitação forem idênticos nos contextos diversos aos constatados nos textos primeiros, se valida a ideia de que todas as épocas são iguais. Se todas as épocas forem distintas, a tautológica excentricidade do Quixote, por exemplo, será resguardada da diversidade de pancadas que recebe ao longo do texto primeiro, independentemente do novo contexto; faria-o, em Wall Street, potencial paciente do New York State Psychiatric Institute.

Independentemente se prevalece "la idea primaria de que todas las épocas son iguales o de que son distintas" (BORGES, 1974b, p. 446), o que se constata é a tendência de a segunda enunciação, mesmo diversa, elaborar-se como reforço à primeira, o que conspira a favor da leitura unívoca. Se o livro parasitário (na má acepção do qualificativo) ${ }^{16}$ funda-se no redundante caráter que estabelece a personagem deslocada, a segunda enunciação subordina-se à enunciação primeira. Um mundo totalmente insensível à misericórdia de Cristo ainda põe em primeiro plano a misericórdia fundamental. Esse acordo, proposto e prontamente aceito senão pela segunda enunciação, se observado pela ética do anacronismo de Menard, parece vazio de responsabilidade histórica e crítica.

É a qualidade de sempre atualizado no nível da enunciação (ou a presença de uma dupla enunciação, de uma segunda camada que envelopa e critica a primeira) que garante à técnica do anacronismo deliberado de Borges, sua perspectiva histórica, de texto que lê a história (a tradição, seus precursores) e que nela se insere; um paralelo que antecipa o que defenderia Kristeva (1968, p. 311) décadas depois ao tratar da relação intertextual.

No prólogo de Discusión, ao comentar dois de seus ensaios na coletânea, Borges (1974a, p. 177) explica o funcionamento histórico de

${ }^{16}$ Alan Pauls (2004, p. 103-105) expõe e analisa uma crítica, a princípio depreciativa, com a qual, em 1933, Ramón Doll ataca Borges e seu livro de ensaios Discusión (1932). Doll afirma que Borges é autor de uma literatura parasitária, que tenta legitimar um vício (a negligência em repetir o que já foi escrito) e um crime (o plágio). Pauls afirma que, antecipando-se a seu crítico, Borges já havia convertido o parasitismo (ou revertido o potencial ataque) na força de um programa artístico próprio. Em "O crítico como hospedeiro”, Hillis Miller (1995a, p. 13-16) vale-se da metáfora biológica e social do parasita, e de seus congêneres hóspede e hospedeiro, para explicar a relação travada entre poeta e crítico e os textos primeiros que acionam por meio de citações, alusões e ecos para compor suas próprias obras. O pesquisador propõe que essa relação é antitética duplamente: ao mesmo tempo em que se alimentam do outro texto, poeta e crítico - seus textos - também lhe servem de alimento. A relação é fendida, de apropriação e entrega, de manutenção e destruição mútuas. 
seus "resignados ejercicios de anacronismo: no restituyen el difícil pasado - operan y divagan con él”. Por mais extensas que sejam as repetições perpetradas por Menard, capítulos inteiros do Quixote de Miguel de Cervantes (ainda que não surjam plenamente transcritos no conto de Borges), Menard nunca será Cervantes, tampouco são os mesmos os textos que produzem (assim como uma hipotética Roma apreciada no final do século XIX por um simbolista não seria a Roma do século I, mesmo que ainda se discorresse sobre Nero). O desconcertante no anacronismo é "a não-simultaneidade do simultâneo" (EZENSBERGER, 2003, p. 12), justamente a irredutível diferença entre os estatutos do enunciado e da enunciação, que coabitam o discurso. Por isso Menard "no encaró nunca una transcripción mecánica del original; no se proponía copiarlo" (BORGES, 1974b, p. 446). Os anacronismos deliberados são críticos, são conhecedores do contexto em que se dão suas enunciações, "operan y divagan” acerca das enunciações com os mesmos enunciados efetuadas no passado e no presente.

Por tais motivos, o plágio, como aqui o apresentamos, é impossível sob a ética do anacronismo. O plágio é "inócuo quanto ao efeito da nova estrutura: desprovido da intenção da recriação, de renovação, de proposta crítica" (OLIVAL, 1998, p. 53). A própria forma do conto "Pierre Menard, autor del Quijote" é indício da atualização efetivada pelo personagem-autor. $\mathrm{O}$ texto inicia-se com o narrador propondo a revisão bibliográfica de Menard. Ela é necessária, especialmente, porque sua criação mais relevante, sua obra invisível, não aparece no "catálogo falaz" (BORGES, 1974b, p. 444), na lista preparada e publicada por Madame Henri Bachelier, líder do grupo rival na disputa pelo espólio intelectual do falecido escritor. Portanto, o narrador manifesta-se pela atribuição de autoria; Menard é o autor do Quixote, o que não impede que a presença do heterogêneo, Cervantes e seu romance, seja amplamente marcada (por Borges, antes de todos). Menard nunca desejou plagiar, "usurpar o direito à estrutura de origem” (OLIVAL, 1998, p. 53), o que colocaria em xeque sua propriedade. Sua empresa tem como fundamento o fato de "seguir siendo Pierre Menard y llegar al Quijote, a través de las experiencias de Pierre Menard” (BORGES, 1974b, p. 447). Anacrônica, não há, em qualquer das linhas da ars magna de Menard, indício da configuração de plágio. A distância temporal, "el olvido y la indiferencia” (BORGES, 1974b, p. 448), a resignada situação posposta por sua própria enunciação em relação ao Quixote de Cervantes (enfim, o anacronismo) permitem a Menard a reflexão: 
Componer el Quijote a principios del siglo diecisiete era una empresa razonable, necesaria, acaso fatal; a principios del veinte, es casi imposible. No en vano han transcurrido trescientos años, cargados de complejísimos hechos. Entre ellos, para mencionar uno solo: el mismo Quijote (BORGES, 1974b, p. 448).

A quase certa impossibilidade de composição do Quixote no século XX não implica em impossibilidade de leitura (releitura, reescrita). Menard opera aquilo que Compagnon (1996, p. 14) chama de leitura não unificadora e não passiva, por excelência "um ato de citação que desagrega o texto e o destaca do contexto". Há profundas implicações em citar: "Quando cito, extraio, mutilo, desenraizo" (COMPAGNON, 1996, p. 13). Estamos diante de um exercício fundamentalmente anacrônico. Agindo sob a ética do anacronismo deliberado, Menard quer fragmentos do Quixote, não a mera cópia ou a tautologia: ser Cervantes e escrever o Quixote não lhe interessam. E avança: não se satisfaz apenas com a citação direta; citar e glosar são as tarefas que fazem dele um ajuizado crítico literário. Para Claire de Obaldia (2005, p. 395), a citação, a interpolação e a digressão, processos da constante recontextualização das linhas do Quixote, fazem de Menard um genuíno ensaísta.

Assim, o caráter crítico e histórico do anacronismo deliberado: uma segunda enunciação, ciente de sua força e lugar, que envelopa a primeira enunciação e seu enunciado (ou uma rede de enunciações e enunciados congêneres ou conflitivos) para assim lê-los, colocá-los em contato com os diversos fragmentos que formam a enciclopédia de seu operador (a tradição e os precursores por ele eleitos). $\mathrm{O}$ fragmento aqui anacronicamente (e virtualmente) lido torna-se passível de integrar a biblioteca do leitor, a depender de como nela se acomoda.

Por outro lado, o acrítico anacronismo tautológico: um segundo enunciado que apenas redunda, reforça a primeira enunciação e seu enunciado (ou uma rede de enunciações e enunciados congêneres ou conflitivos, para, ao final, privilegiar uma das tendências discursivas). Esse acordo é proposto e prontamente aceito senão pela segunda enunciação.

\section{WHITMAN, ANACRÔNICO}

Em "Nota sobre Walt Whitman", ${ }^{17}$ Borges localiza uma estratégia de composição elaborada pelo autor ensaiado que vence o tempo, cujo passar

${ }^{17}$ Publicado pela primeira vez em Los anales de Buenos Aires, ano 2, n. 13, mar. 1947. "Nota sobre Walt Whitman” foi incluído em algumas edições de Otras inquisiciones e na segunda edição de Discusión, obra na qual permaneceu na publicação das Obras completas (1974). 
dos anos não foi capaz de diminuir. Por tal qualidade (esse virtuoso exercício de anacronismo, como atestaremos adiante), é comparado por Borges à ambiciosa ideia do livro absoluto, "un libro de los libros que incluya a todos como un arquetipo platónico" (BORGES, 1974a, p. 249). Vários autores de diferentes épocas se aproximam desse arquétipo, entre eles "Joyce, en Finnegans Wake, mediante la simultánea presentación de rasgos de épocas distintas. El deliberado manejo de anacronismos, para forjar una apariencia de eternidad, también ha sido practicado por Pound y por T. S. Eliot" (BORGES, 1974a, p. 249). Porém, a manipulação da eternidade proposta por Whitman é, segundo Borges, o mais curioso dos que localizou.

Sua primeira qualidade é a de superar, de quase invalidar, qualquer exercício, baseado na fidelidade, de aferição da identificação entre biografia e bibliografia: os leitores, críticos e biógrafos que tentam aproximar ou afastar o homem Whitman da lenda Whitman, "héroe semidivino de Leaves of Grass" (p. 250), incorrem em um errôneo e inócuo exercício, como o daqueles que buscam pontos de convergência e divergência entre o romance de Dostoiévski e as adaptações de Irmãos Karamazov ao cinema, descrito em "Films". Isso porque "Whitman, con impetuosa humildad, quiere parecerse a todos los hombres" (p. 250), de todas as terras e de todas as épocas. Borges sustenta seu argumento recorrendo ao texto poético de Whitman que ele mesmo traduz:

Éstos son en verdad los pensamientos de todos los Hombres en todos los lugares y épocas; no son originales míos.

Si son menos tuyos que míos, son nada o casi nada.

Si no son el enigma y la solución del enigma, son nada.

Si no están cerca y lejos, son nada.

Éste es el pasto que crece donde hay tierra y hay agua,

Éste es el aire común que baña el planeta (WHITMAN [s.d.] apud BORGES, 1974a, p. 251). ${ }^{18}$

18 "These are really the thoughts of all men in all ages and lands, the are not original with me,/ If they are not yours as much as mine they are nothing, or next to nothing,/ If they are not the riddle and the untying of the riddle they are nothing,/ If they are not just as close as they are distant they are nothing.// This is the grass that grows wherever the land is and the water is,/ This the common air that bathes the globe." (WHITMAN, 1897, p. 43). "Estes são os pensamentos de todos os homens em todos os tempos e terras, não se originam em mim,/ Se eles não são seus tanto quanto meus, eles são nada ou quase nada,/ Se eles não são o enigma ou a resposta, eles são nada,/ Se eles não são a um só tempo próximos e distantes, eles são nada.// Esta é a grama que cresce onde quer que exista terra e água,/ Este é o ar comum que banha o globo." (WHITMAN, 2011, p. 57). Apesar de não remeter ao volume do livro de Whitman que consulta, é reconhecível que Borges traduz e cita a partir de uma edição de Leaves of grass que imprime a versão definitiva do texto, a da segunda edição de 1891. 
Yo soy el hombre. Yo sufrí. Ahí estaba.

El desdén y la tranquilidad de los mártires;

La madre, sentenciada por bruja, quemada ante los hijos, con leña seca;

El esclavo acosado que vacila, se apoya contra el cerco, jadeante, cubierto de sudor;

Las puntadas que le atraviesan las piernas y el pescuezo, las crueles municiones y balas;

Todo eso lo siento, lo soy (WHITMAN [s.d.] apud BORGES, 1974a, p. 251-252). ${ }^{19}$

Estamos diante de um princípio de identidade de outra espécie, não como o da hermenêutica de Novalis, da presença de um pelo outro, que Pierre Menard experimenta e logo descarta por avaliá-lo fácil e insuficiente para sua empresa, genuinamente crítica, não meramente interpretativa. Tampouco é uma variação tradicional do panteísmo, mas uma identificação totalmente renovada, defende Borges (1974a, p. 251): "No lo ejerció, como otros, para definir la divinidad o para jugar con las 'simpatías y diferencias' de las palabras; quiso identificarse, en una suerte de ternura feroz, con todos los hombres". Suas enumerações e listas de itens díspares e suas convergências de inconciliáveis respondem ao projeto estético de Leaves of grass, que nos termos do próprio Whitman, como recorda Borges (1974a, p. 250-251), "é o canto de um grande indivíduo coletivo e popular, homem ou mulher".

Dentre os diversos trechos de Leaves of grass traduzidos e transcritos por Borges em seu ensaio, destacamos Full oflife now, surpreendentemente anacrônico. Whitman foi, na leitura empreendida por Borges, um profeta capaz de anunciar a nostalgia do porvir:

Lleno de vida, hoy, compacto, visible,

Yo, de cuarenta años de edad el año ochenta y tres de los Estados,

A ti, dentro de un siglo o de muchos siglos,

A ti, que no has nacido, te busco.

Estás leyéndome. Ahora el invisible soy yo,

Ahora eres tú, compacto, visible, el que intuye los versos y el que me busca,

Pensando lo feliz que sería si yo pudiera ser tu compañero.

19 "I am the man, I suffer'd, I was there.// The disdain and calmness of martyrs,/ The mother of old, condemn'd for a witch, burnt with dry wood, her children gazing on,/ The hounded slave that flags in the race, leans by the fence, blowing, cover'd with sweat,/ The twinges that sting like needles his legs and neck, the murderous buckshot and the bullets,/ All these I feel or am." (WHITMAN, 1897, p. 59-6o). "Eu sou o homem, eu sofri, eu estava lá.// O desdém e a calma dos mártires,/ a mãe idosa, condenada como bruxa e queimada como as madeiras secas e as crianças assistindo,/ O escravo perseguido que cansa de correr, encosta na cerca, ofegante, coberto de suor,/ As fisgadas que ferem suas pernas e seu pescoço como agulhas, o tiro mortal e as balas,/ Todas essas coisas eu sinto ou sou." (WHITMAN, 2011, p. 73). 
Sé feliz como si yo estuviera contigo. (No tengas demasiada seguridad de que no estoy contigo.) (WHITMAN [s.d.] apud BORGES, 1974a, p. 25220

O leitor, na proposta de Whitman (ou na leitura que assume a proposta de Borges lendo Whitman), ${ }^{21}$ é aquele a quem o autor atribui a responsabilidade de estabelecer o texto: "Now it is you, compact, visible, realizing my poems". Atribuir essa citação de Withman a Borges, exercício de anacronismo, ativa o estoque de cores: se de fato "los buenos lectores son cisnes aun más tenebrosos y singulares que los buenos autores" (BORGES, 1974c, p. 289), o são porque operam a literatura de forma crítica, recordando-a e fazendo-a permanentemente viva. "A literatura se escreve com a lembrança daquilo que é, daquilo que foi. Ela a exprime, movimentando sua memória e a inscrevendo nos textos por meio de um certo número de procedimentos de retomadas, de lembranças e de re-escrituras" (SAMOYAULT, 2008, p. 47). Contudo, é mais que isso. Essa manifestação não está subordinada a uma unidirecionalidade temporal: "As obras literárias nunca são simples memórias - reescrevem as suas lembranças, influenciam os seus precursores, como diria Borges" (JENNY, 1979, p. 10). Nunca é passiva a reescritura efetuada sobre os precursores e sobre a tradição.

Valendo-se do deliberado anacronismo, esta complexa ferramenta de reconfiguração, reordenação e combinação de textos alheios, os leitores

${ }_{20}$ "Full of life now, compact, visible,/ I, forty years old the eighty-third year of the States,/ To one a century hence or any number of centuries hence,/ To you yet unborn these, seeking you.// When you read these I that was visible am become insvisible,/ Now it is you, compact, visible, realizing my poems, seeking me,/ Fancying how happy you were it I could be with you and become your comrade;/ Be it as if I were with you. (Be not too certain but I am now with you.)" (WHITMAN, 1897, p. 111-112). "Cheio de vida agora, compacto, visível,/ Eu, quarenta anos de idade no octogésimo terceiro ano dos Estados,/ Para alguém um século à frente ou sem um número de séculos à frente,/ Para você ainda não nascido, estas canções à sua procura.// Quando você ler estas canções eu que era visível me torno invisível,/ Agora é você, compacto, visível, realizando meus poemas, me procurando,/ Fantasiando quão feliz você seria se eu estivesse com você e me tornasse seu camarada;/ Que seja como se eu estivesse com você. (Não esteja tão certo, mas estou agora com você)." (WHITMAN, 2011, p. 123).

${ }^{21}$ Segundo Bernucci (200o, p. 8o-81), como poeta, e mesmo como crítico, ao escrever sobre outros autores (Whitman, Kafka, Stevenson, Coleridge, Shakespeare, Cervantes, Valéry, Wells, Joyce etc.), Borges simultaneamente escreve sobre si. Portanto, na leitura que realizamos, ao falar de procedimentos operados por Whitman, Borges fala de técnicas caras a ele e à sua escrita. 
atuam como Milton, que "teme haber nacido demasiado tarde para la épica (demasiado lejos de Homero, demasiado lejos de Adán)” (BORGES, 1974a, p. 264), mas que, apesar disso (ou justamente por isso), não deixa de exercitar seus versos. "Leer, por lo pronto, es una actividad posterior a la de escribir: más resignada, más civil, más intelectual” (BORGES, 1974C, p. 289). O leitor não passivo é aquele sempre apto à reescrita e o anacronismo deliberado, seu motor.

\section{REFERÊNCIAS BIBLIOGRÁFICAS}

BERNUCCI, Leopoldo. Biografia e visões especulares: Borges e Dante. In: Borges no Brasil (org.: Jorge Schwartz). São Paulo: Editora Unesp: Imprensa Oficial do Estado, 2001, p. 77-100.

BORGES, Jorge Luis. Discusión. In: . Obras completas: 1923-1972. Buenos Aires: Emecé, 1974a, p. 173-286.

BORGES, Jorge Luis. Ficciones. In: Obras completas: 1923-1972. Buenos Aires: Emecé, 1974b, p. 425-530.

BORGES, Jorge Luis. Historia universal de la infamia. In: -1972. Buenos Aires: Emecé, 1974c, p. 287-345.

BORGES, Jorge Luis. Cine: cinco breves noticias. In: Barcelona: Emecé, 2002a, p. 44-45. . Obras completas: 1923-

BORGES, Jorge Luis. La eternidad y T. S. Eliot. In: Barcelona: Emecé, 2002b, p. 49-52. . Textos recobrados: 1931-1955.

COMPAGNON, Antoine. O trabalho da citação. Tradução de Cleonice Paes Barreto Mourão. Belo Horizonte: UFMG, 1996.

DE OBALDIA, Claire. L'esprit de l'essai: de Montaingne à Borges. Tradução de Émilie Colombani. Paris: Seuil, 2005.

ELIOT, T. S. Ensaios. Tradução de Ivan Junqueira. São Paulo: Art, 1989.

EZENSBERGER, Hans Magnus. A massa folhada do tempo: meditações sobre o Anacronismo. In: . Ziguezague: ensaios. Tradução de Marcos José Cunha. Rio de Janeiro: Imago, 2003, p. 9-26.

FERNANDES, Fabiano Seixas. Bibliografia Jorge Luis Borges, 1910-2003: relação cronológica dos textos e livros. Fragmentos. Florianópolis, UFSC, n. 28-29, p. 225-431, jan.-dez. 2005. 
HILLIS MILLER, Joseph. O crítico como hospedeiro. In: - A ética da leitura: ensaios 1979-1989. Tradução de Eliane Fittipaldi e Kátia Orberg. Rio de Janeiro: Imago, 1995a, p. 11-49.

HILLIS MILLER, Joseph. A ética da leitura. In: A ética da leitura: ensaios 1979-1989. Tradução de Eliane Fittipaldi e Kátia Orberg. Rio de Janeiro: Imago, 1995b, p. $73-88$.

JENNY, Laurent. A estratégia da forma. Tradução de Clara Crabbé Rocha. Poétique. Coimbra, Almedina, n. 27, p. 5-49, 1979.

KRISTEVA, Julia. Théorie d'ensemble. Paris: Seuil, 1968.

OLIVAL, Moema de Castro e Silva de. Intertextualidade ou plágio? In: O espaço da crítica: panorama atual. Goiânia: UFG, 1998, p. 45-55.

PAULS, Alan. El factor Borges. Barcelona: Anagrama, 2004.

RODRÍGUEZ MONEGAL, Emir. Borges: uma poética da leitura. Tradução de Irlemar Chiampi. São Paulo: Perspectiva, 1980.

ROJAS, Carlos. "El acercamiento a Almotásim" y el efecto de contaminación. Variaciones Borges. Pittsburgh, University of Pittsburgh, n. 23, p. 115-127, abr. 2007.

SAMOYAULT, Tiphaine. A intertextualidade. Tradução de Sandra Nitrini. São Paulo: Aderaldo \& Rothschild, 2008.

STAVANS, Ilian (org.). The Oxford book of Latin American essays. New York: Oxford University Press, 1997.

THE SIGN of the cross. Direção e produção de Cecil B. DeMille. Intérpretes: Fredric March, Elissa Landi, Claudette Colbert, Charles Laughton e outros. Roteiro: Waldemar Young e Sidney Buchman. Baseado na peça de Wilson Barrett. [S.l.]: Universal Studios, 2011. 1 DVD (126 minutos), sonoro, preto e branco. Legendado. Inglês/Francês/Espanhol.

WHITE, Peter. 'Tradition and the individual talent' revisited. The Review of English Studies, New Series. Oxford, Oxford University Press, v. 58, n. 235, p. 364-392, jun. 2007.

WHITMAN, Walt. Leaves of grass. London: G. P. Putnam's Sons; Boston: Small, Maynard \& Company, 1897. Edição fac-similar. Disponível em: https://ia6oo402.us.archive.org/11/ items/leavesgrasso6whitgoog/leavesgrasso6whitgoog.pdf. Acesso em: 20 ago. 2015.

WHITMAN, Walt. Folhas da relva. Edição do leito de morte. Trad. Bruno Gambarotto. São Paulo: Hedra, 2011. 